\title{
Short-term knemometry and urine cortisol excretion in children treated with fluticasone propionate and budesonide: a dose response study
}

\author{
L. Agertoft, S. Pedersen
}

Short-term knemometry and urine cortisol excretion in children treated with fluticasone propionate and budesonide: a dose response study. L. Agertoft, S. Pedersen. (CERS Journals Ltd 1997.

ABSTRACT: Few thorough comparisons of the systemic effects of inhaled corticosteroids in children are available. The aim of this study was to compare the effect of budesonide and fluticasone propionate on short-term lower leg growth.

Fluticasone propionate, budesonide and placebo were administered for 2 weeks in a randomized, double-blind, double-dummy, cross-over design. Twenty four children aged 6-12 yrs received $200 \mu \mathrm{g} \cdot \mathrm{day}^{-1}$ of each drug, or placebo. Another 24 children aged 6-12 years received $400 \mu \mathrm{g} \cdot \mathrm{day}^{-1}$ of each drug, or placebo. Dry powder inhalers were used. Lower leg length was measured by knemometry twice a week during all three treatment periods, and $24 \mathrm{~h}$ cortisol excretion in the urine was measured at the end of each period.

In the low-dose group, lower leg growth rate was the same during treatment with placebo $\left(0.35 \mathrm{~mm} \cdot\right.$ week $\left.^{-1}\right)$, fluticasone propionate $\left(0.38 \mathrm{~mm} \cdot\right.$ week $\left.^{-1}\right)$ or budesonide $\left(0.26 \mathrm{~mm} \cdot\right.$ week $\left.^{-1}\right)$. No significant difference $(p=0.39)$ in lower leg growth rate was found between treatment with $400 \mu \mathrm{g} \cdot$ day $^{-1}$ budesonide $\left(0.30 \mathrm{~mm} \cdot\right.$ week $\left.^{-1}\right)$ and $400 \mu \mathrm{g}$ fluticasone propionate treatment $\left(0.37 \mathrm{~mm} \cdot\right.$ week $\left.^{-1}\right)$. Growth rate during treatment with budesonide, $400 \mu \mathrm{g} \cdot \mathrm{day}^{-1}$, was significantly lower than during placebo treatment $\left(0.52 \mathrm{~mm} \cdot\right.$ week $\left.^{-1}\right)$. Cortisol excretion in the urine during treatment with $200 \mu \mathrm{g} \cdot \mathrm{day}^{-1}$ fluticasone propionate was significantly reduced as compared with placebo $(\mathrm{p}=\mathbf{0 . 0 0 6})$, but not when compared with $200 \mu \mathrm{g} \cdot \mathrm{day}^{-1}$ budesonide $(p=0.07)$. Budesonide $200 \mu \mathrm{g} \cdot \mathrm{day}^{-1}$ was not significantly different from placebo. Fluticasone propionate and budesonide, both at $400 \mu \mathrm{g} \cdot \mathrm{day}^{-1}$, resulted in a significant reduction in cortisol excretion in the urine as compared with placebo $(p=0.001)$.

It is concluded that, dose-for-dose, budesonide Turbuhaler and fluticasone propionate Diskhaler have similar systemic effects.

Eur Respir J 1997; 10: 1507-1512.

As inhaled glucocorticosteroids (GCS) are increasingly used for prophylaxis in childhood asthma, new inhaled products with high topical potency and low systemic effects are being developed. Fluticasone propionate and budesonide are the two latest examples of this development. Both have been shown to be clinically very effective at low doses [1-3]. However, few thorough comparisons of their systemic effects in children are available.

Recently, knemometry has become established as an integral part of the available measures of systemic activity of topical steroids in children [4-8]. By measuring changes in lower leg length with an accuracy of $0.09-0.1 \mathrm{~mm}$, the knemometer provides a powerful tool for investigating the influence of exogeneous GCS on short-term lower leg growth. In addition, accurate assessment of cortisol excretion in the urine has also been shown to be a sensitive marker of the systemic effect of exogenous steroids [8,9].

The aim of this study was to compare the systemic effects of daily doses of 200 and $400 \mu \mathrm{g}$ fluticasone propionate Diskhaler and budesonide Turbuhaler in children with mild asthma, by measuring short-term lower
Dept of Paediatrics, Kolding Hospital, Kolding, Denmark.

Correspondence: L. Agertoft

Dept of Paediatrics

Kolding Hospital

DK-6000 Kolding

Denmark

Keywords: Asthma

children

inhaled steroids

knemometry

urine cortisol

Received: August 201996

Accepted after revision February 281997 leg growth using knemometry and $24 \mathrm{~h}$ cortisol excretion in the urine.

\section{Patients and methods}

The study was a randomized, double-blind, two-limbed trial with three treatment periods and two wash-out periods in each limb (fig. 1). One group of children was randomized to treatment with placebo, fluticasone propionate, $200 \mu \mathrm{g} \cdot \mathrm{day}^{-1}$, and budesonide $200 \mu \mathrm{g} \cdot \mathrm{day}^{-1}$, in a randomized, cross-over fashion. Another group received placebo, fluticasone propionate, $400 \mu \mathrm{g} \cdot \mathrm{day}^{-1}$, or budesonide $400 \mu \mathrm{g} \cdot \mathrm{day}^{-1}$, in a similar manner. The treatment order and dose was allocated by a computerized randomization scheme prepared in balanced blocks. Throughout the whole study, the children used inhaled $\beta_{2}$-agonists as-needed. No other medication was allowed. The wash-out periods were of 2 week duration and the treatment periods were each 15-18 days long. The design was a double-dummy study. Each child took both one blister from the dry powder inhaler Diskhaler (fluticasone/placebo) and one dose from the dry powder 
FP/Bud/Pla $200 \mu \mathrm{g} \cdot \mathrm{day}^{-1}$

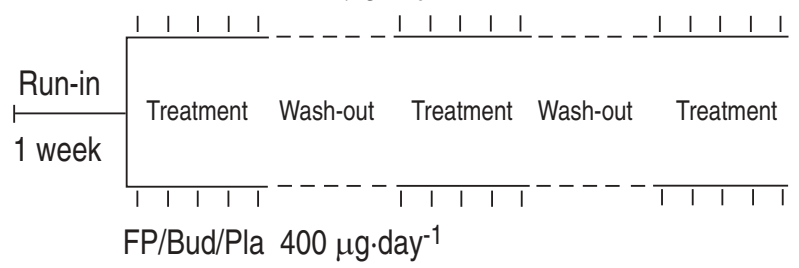

Urine $\uparrow \uparrow$

Fig. 1. - Study design. A randomized, double-blind, cross-over, two-limbed trial with three treatment periods and two wash-out periods in each limb. One group of children was randomized to treatment with placebo (Pla), fluticasone propionate (FP; $200 \mu \mathrm{g} \cdot \mathrm{day}^{-1}$ ), or budesonide (Bud; $200 \mu \mathrm{g} \cdot \mathrm{day}^{-1}$ ). Another group received placebo, fluticasone propionate $\left(400 \mu \mathrm{g} \cdot \mathrm{day}^{-1}\right)$, or budesonide $\left(400 \mu \mathrm{g} \cdot \mathrm{day}^{-1}\right)$. Knemometry was performed twice a week during the treatment periods. The duration of each treatment and wash-out period was 2 weeks. Blood and urine samples were taken at the intervals shown by the arrows.

inhaler Turbuhaler (budesonide/placebo) morning and evening. Before the study, all children had been taught the correct inhalation technique with both inhalers, and the inhalation technique was checked at each visit. To assess compliance, the number of blisters consumed and the number of doses left in the Turbuhaler were counted at the end of each period.

When planning the study, the SD of the mean lower leg growth rate was estimated to be $0.1 \mathrm{~mm} \cdot$ week $^{-1}$. Based on this assumption, it was estimated that 20 patients in each group would be sufficient for a power of $>0.90$ to detect a $20 \%$ difference in growth rate within each limb of the study. As some withdrawals were to be expected, the study population of each group was increased by 4 patients.

Forty eight children, out-patients in a secondary referral centre, entered the study. All had mild asthma, requiring only treatment as-needed with inhaled $\beta_{2^{-}}$ stimulants. None had received treatment with inhaled or oral GCS for 2 months before the study, and no other drug was taken during the study period. All children were pre-adolescent Caucasian without any signs of puberty. Table 1 presents the data of the patients studied. The study was approved by the local Ethics Committee and informed consent was obtained from all children and their parents.

Knemometry of the right lower leg was scheduled twice weekly using a knemometer manufactured by the inventor. All measurements were performed by the same trained observer who was unaware of the recordings of the previous visit. The children were measured at approximately the same time (i.e. within $30 \mathrm{~min}$ ) in the afternoon (between 14.00 and $19.00 \mathrm{~h}$ ), as recommended for knemometry. The children were not allowed to exercise for $2 \mathrm{~h}$ prior to the visit. After arrival at the clinic, they rested for $10 \mathrm{~min}$ before their lower leg length was measured. At each visit, four estimates of the length of the lower leg were made. The most deviant value was disregarded, and the mean of the three remaining measurements was used for analysis. In addition, height (Harpenden stadiometer) and weight (electronic beam analyser) were also recorded.

Forced expiratory volume in one second (FEV1) was measured with a dry wedge spirometer (Vitalograph) at
Table 1. - Patient characteristics in the two study groups

\begin{tabular}{lcc}
\hline & $200 \mu$ group & $400 \mu \mathrm{g}$ group \\
\hline Sex M/F & $11 / 13$ & $16 / 8$ \\
Age yrs & 9 & 9 \\
& $(6-12)$ & $(6-12)$ \\
Height cm & 140 & 138 \\
& $(121-161)$ & $(118-161)$ \\
Weight $\mathrm{kg}$ & 36 & 36 \\
Asthma duration yrs & $(23-60)$ & $(23-61)$ \\
& 2.1 & 2.2 \\
Growth during previous & $(0-10)$ & $(0-10)$ \\
year cm & 5.7 & 5.6 \\
\hline
\end{tabular}

Values are presented as mean, and range in parenthesis. M: male; F: female.

each visit, the best of three measurements being used for analysis. Throughout the study, peak expiratory flow $(\mathrm{PEF})$ rate was measured at home in the morning and evening (best of three values with a mini-Wright peak flow meter). In addition, the use of inhaled $\beta_{2}$-stimulants and asthma symptoms during the night and day were recorded in diaries. To minimize the risk of a possible suppressive effect of reduced pulmonary function on growth, only data from children showing less than $10 \%$ variation in pulmonary function between various periods were analysed. At the end of each treatment period, $24 \mathrm{~h}$ urine samples were collected for analysis of cortisol and creatinine excretion. Cortisol in the urine was measured by a radioimmunoassay (RIA) method with an intra- and interassay coefficient of variation of 7.2 and $6.7 \%$, respectively.

At each visit, a thorough physical examination was carried out to detect any intercurrent illness or disorder which might interfere with linear growth.

Twenty three children in the low-dose group and 24 children in the high-dose group completed the study according to the protocol. They visited the clinic 824 times, and a total of 3,296 lower leg measurements were made. One patient was withdrawn during treatment period 1 (fluticasone propionate) in the low-dose group due to an adverse event (sore throat). No period or carry-over effects were seen.

The technical error of the knemometer (i.e. the mean SD of three successive estimations of lower leg length) was $0.07 \mathrm{~mm}$.

\section{Statistical analysis}

Growth velocities of the lower leg were calculated for each period by linear regression analysis and expressed as $\mathrm{mm} \cdot \mathrm{week}^{-1}$. The results from the various treatment periods were analysed using analysis of covariance (ANCOVA) techniques, allowing for variation due to treatment sequence, patients (within sequence), periods, and treatment. Tests for carry-over effects were also performed. The data did not need transformation on the log scale to satisfy the assumptions behind the ANCOVA.

\section{Results}

Few symptoms were reported and lung functions were high during all treatment periods. No significant variations were seen in these parameters between the various treatments. Morning PEF in the low-dose group 
varied from 300 to 310 and $306 \mathrm{~L} \cdot \mathrm{min}^{-1}$ during placebo, fluticasone propionate and budesonide treatment, respectively. The corresponding values in the $400 \mu \mathrm{g}$ group were 289, 302 and $300 \mathrm{~L} \cdot \mathrm{min}^{-1}$. Evening PEF values in the $200 \mu \mathrm{g}$ group were 305,310 and 311 $\mathrm{L} \cdot \mathrm{min}^{-1}$, during placebo, fluticasone propionate and budesonide, respectively. The corresponding values in the $400 \mu \mathrm{g}$ group were 299,308 and $306 \mathrm{~L} \cdot \mathrm{min}^{-1}$.

Figure 2 shows the individual and mean lower leg growth velocities during the three treatment periods in the low- and high-dose groups. The results of the statistical analysis are presented in table 2 . There was no statistically significant difference between mean lower leg growth rate during the three treatments in the lowdose group $\left(\mathrm{Pla}=0.35 ; \mathrm{FP}=0.38 ; \mathrm{Bud}=0.26 \mathrm{~mm} \cdot \mathrm{week}^{-1}\right)$. In the high-dose group, growth rate during both treatments $\left(\mathrm{Bud}=0.30 ; \mathrm{FP}=0.37 \mathrm{~mm} \cdot\right.$ week $\left.^{-1}\right)$ was somewhat reduced as compared with placebo $\left(0.52 \mathrm{~mm} \cdot\right.$ week $\left.^{-1}\right)$. The reduction in rate was significant compared to placebo for budesonide but not for fluticasone. There was no statistically significant difference between the growth rates measured during budesonide and fluticasone propionate treatments, in either the low-dose group or in the high-dose group.

Mean urinary cortisol excretion, corrected for creati- nine excretion, during the various treatment periods is presented in table 2. Cortisol excretion during treatment with $200 \mu \mathrm{g}$ fluticasone propionate (10.1) was significantly reduced as compared with placebo (13.8). Treatment with budesonide $200 \mu \mathrm{g}$ did not influence urinary cortisol excretion (12.4). High-dose treatment with both fluticasone propionate (9.5) and budesonide (10.3) resulted in statistically significant reductions in cortisol excretion in the urine as compared with placebo (12.8). No significant differences were seen between the cortisol excretion during treatment with the two steroids, either in the low-dose group or in the high-dose group.

Creatinine excretion in urine was similar in all treatment periods (mean $\pm \mathrm{sD}$ ): $200 \mu \mathrm{g} \cdot \mathrm{day}^{-1}$ placebo $5.35 \pm$ $1.9 \mathrm{mmol} \cdot$ day $^{-1} ; 200 \mu \mathrm{g} \cdot \mathrm{day}^{-1}$ fluticasone propionate $6.17 \pm 2.5 \mathrm{mmol} \cdot$ day $^{-1} ; 200 \mu \mathrm{g} \cdot \mathrm{day}^{-1}$ budesonide $5.43 \pm 1.8$ $\mathrm{mmol} \cdot \mathrm{day}^{-1} ; 400 \mu \mathrm{g} \cdot \mathrm{day}^{-1}$ placebo $5.79 \pm 1.7 \mathrm{mmol} \cdot \mathrm{day}^{-1}$; $400 \mu \mathrm{g} \cdot \mathrm{day}^{-1}$ fluticasone propionate $6.13 \pm 2.4 \mathrm{mmol} \cdot \mathrm{day}^{-1}$; $400 \mu \mathrm{g} \cdot$ day $^{-1}$ budesonide $5.83 \pm 2.16 \mathrm{mmol} \cdot$ day $^{-1}$, and the conclusions were the same for the absolute values of cortisol excretion as for the creatinine-corrected values.

Compliance, assessed by counting the number of unused doses after each period, was high and there was no statistically significant difference between the two drug/inhaler combinations (it was higher than $80 \%$ in $96 \%$ of
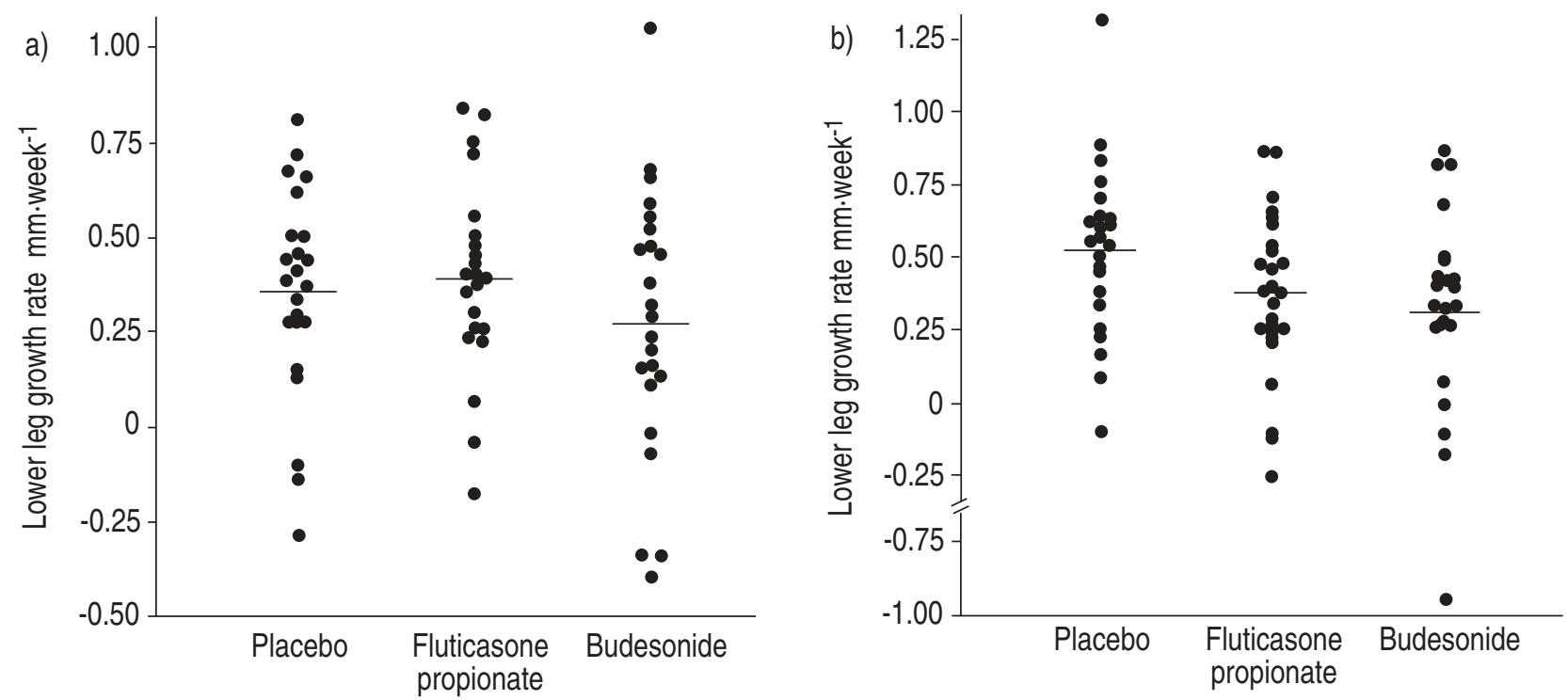

Fig. 2. - Individual and mean lower leg growth rate: a) during treatment with placebo, fluticasone propionate, $200 \mu \mathrm{g} \cdot \mathrm{day}{ }^{-1}$ from Diskhaler, and budesonide, $200 \mu \mathrm{g} \cdot \mathrm{day}^{-1}$ from Turbuhaler; and b) during treatment with placebo, fluticasone propionate, $400 \mu \mathrm{g} \cdot \mathrm{day}{ }^{-1}$ from Diskhaler, and budesonide, $400 \mu \mathrm{g} \cdot \mathrm{day}^{-1}$ from Turbuhaler. Growth rate during budesonide, $400 \mu \mathrm{g} \cdot \mathrm{day}^{-1}$ (b) treatment was significantly reduced as compared with placebo. Otherwise, no statistically significant differences were seen between the various treatments.

Table 2. - Mean lower leg growth rate and urine cortisol excretion corrected from creatinine excretion

\begin{tabular}{|c|c|c|c|c|c|c|}
\hline & Pla & $\mathrm{FP}$ & Bud & $\mathrm{FP} v s \mathrm{Pla}$ & Bud $v s$ Pla & Bud $v s$ FP \\
\hline $\begin{array}{l}\text { Growth } \mathrm{mm} \cdot \text { week }^{-1} \\
200 \mu \mathrm{g} \text { group }\end{array}$ & 0.35 & 0.38 & 0.26 & $\begin{array}{c}0.03(-0.16 ; 0.21) \\
\mathrm{p}=0.77\end{array}$ & $\begin{array}{c}-0.09(-0.28 ; 0.09) \\
\mathrm{p}=0.31\end{array}$ & $\begin{array}{c}-0.12(-0.30 ; 0.06) \\
\mathrm{p}=0.19\end{array}$ \\
\hline $\begin{array}{l}\text { Growth } \mathrm{mm} \cdot \text { week }^{-1} \\
400 \mu \mathrm{g} \text { group }\end{array}$ & 0.52 & 0.37 & 0.30 & $\begin{array}{c}-0.15(-0.32 ; 0.02) \\
\mathrm{p}=0.09\end{array}$ & $\begin{array}{c}-0.22(-0.40 ;-0.05) \\
p=0.01\end{array}$ & $\begin{array}{c}-0.08(-0.25 ; 0.10) \\
\mathrm{p}=0.39\end{array}$ \\
\hline $\begin{array}{l}\text { Cortisol/creatinine } \\
200 \mu \mathrm{g} \text { group }\end{array}$ & 13.8 & 10.1 & 12.4 & $\begin{array}{c}-3.7(-6.2 ;-1.1) \\
\mathrm{p}=0.006\end{array}$ & $\begin{array}{c}-1.3(-3.8 ; 1.3) \\
\mathrm{p}=0.32\end{array}$ & $\begin{array}{c}2.4(-0.2 ; 5.0) \\
\quad p=0.07\end{array}$ \\
\hline $\begin{array}{l}\text { Cortisol/creatinine } \\
400 \mu \mathrm{g} \text { group }\end{array}$ & 12.8 & 9.5 & 10.3 & $\begin{array}{c}-3.2(-4.6 ;-1.8) \\
\mathrm{p}=<0.001\end{array}$ & $\begin{array}{c}-2.5(-3.9 ;-1.1) \\
\mathrm{p}=0.001\end{array}$ & $\begin{array}{c}0.8(-0.7 ; 2.2) \\
\mathrm{p}=0.29\end{array}$ \\
\hline
\end{tabular}

The results of the statistical comparisons are given as mean difference, and 95\% confidence limits in parenthesis. Pla: placebo; FP: fluticasone dipropionate Diskhaler; Bud: budesonide Turbuhaler. 
the children during fluticasone propionate treatment and in $78 \%$ of the children during budesonide treatment, both in the low-dose and the high-dose groups).

No side-effects attributable to the treatments were reported during the study.

\section{Discussion}

Efficacy studies have suggested that fluticasone propionate, $200 \mu \mathrm{g} \cdot \mathrm{day}^{-1}$ from a Diskhaler, is clinically equivalent to beclomethasone, $400 \mu \mathrm{g} \cdot \mathrm{day}^{-1}$, in controlling symptoms [10-12]. Budesonide Turbuhaler has been found to be twice as effective, dose-for-dose, as budesonide from a metered-dose inhaler or a large-volume spacer (Nebuhaler) [13-15]. Furthermore, a recent study found that budesonide Turbuhaler and fluticasone Diskhaler were equally effective, dose-for-dose, in school children with asthma [16].

For these reasons, we decided to compare the systemic effects of the same doses of drug from the two drug/ inhaler combinations. A randomized placebo period was added to make it easier to adjust for period effects, which may sometimes be seen when knemometry measurements are made over long periods of time [4]. We also included a greater number of patients than in our earlier studies in an effort to increase the power of the study. Under these conditions, we found that treatment with $200 \mu \mathrm{g} \cdot \mathrm{day}^{-1}$ of budesonide Turbuhaler or fluticasone propionate Diskhaler was not associated with any detectable adverse effect on lower leg growth rate, in a model which had earlier been shown to be very sensitive in detecting systemic effects of exogenous corticosteroids. This is in agreement with the findings of an earlier study in our clinic with $200 \mu \mathrm{g} \cdot \mathrm{day}^{-1}$ of budesonide Turbuhaler, and a differently designed study with fluticasone, $200 \mu \mathrm{g} \cdot \mathrm{day}^{-1}[17]$.

In contrast, $400 \mu \mathrm{g} \cdot \mathrm{day}^{-1}$ of the two drugs was associated with small systemic effects, which were of the same magnitude for the two drugs. Earlier studies have shown that the systemic effect of inhaled budesonide on lower leg growth rate is dose-related, reaching a significant level at a dose of $800 \mu \mathrm{g} \cdot \mathrm{day}^{-1}$ when taken from a metered-dose inhaler with a spacer (Nebuhaler). None of three studies with budesonide Nebuhaler found any adverse effect of budesonide $400 \mu \mathrm{g} \cdot \mathrm{day}^{-1}$ on lower leg growth $[5,18,19]$. This suggests that dose-for-dose budesonide Turbuhaler has a higher systemic effect than budesonide Nebuhaler. This is in agreement with the findings of an earlier study [20]. Therefore, even if Turbuhaler is twice as effective as Nebuhaler, the therapeutic ratio (clinical effect/systemic effect) is the same.

To our knowledge, the systemic effects of $400 \mu \mathrm{g} \cdot \mathrm{day}^{-1}$ fluticasone Diskhaler in children have not previously been assessed using sensitive measurements in studies with similar statistical power. As for Turbuhaler, the results with fluticasone Diskhaler in the present study cannot be extrapolated to other inhalation devices, unless these devices have exactly the same drug delivery to the intrapulmonary airways as the Diskhaler.

Knemometry is an extremely sensitive measurement for detecting systemic effects of exogenous corticosteroids. For example, prednisolone, $2.5 \mathrm{mg} \cdot \mathrm{day}^{-1}$, or beclomethasone dipropionate, $400 \mu \mathrm{g} \cdot \mathrm{day}^{-1}$, totally stopped lower leg growth rate over a 2 week period, even if these treatments do not have such a pronounced effect on long-term statural growth $[4,6]$. Thus, a significant reduction in lower leg growth rate in a short-term knemometry study cannot be used to predict an adverse effect on long-term statural growth [21], probably due to the nonlinearity of short-term growth and to the diurnal and day-to-day variations in lower leg measurements, and to differences in disease severity [22-25].

In contrast, knemometry is very useful for defining doses of inhaled corticosteroids which are most unlikely to be associated with any adverse effect on long-term statural growth [25]. At present, long-term statural growth has not been assessed during treatment with $400 \mu \mathrm{g}$. day $^{-1}$ budesonide Turbuhaler or fluticasone Diskhaler. However, in agreement with the present study, fluticasone, 100 and $200 \mu \mathrm{g} \cdot \mathrm{day}^{-1}$, did not adversely affect statural growth when given continuously for a year to schoolchildren [26-28]. Similarly, budesonide 400-600 $\mu \mathrm{g} \cdot \mathrm{day}^{-1}$ from Nebuhaler, metered-dose inhaler, or 300 $\mu \mathrm{g} \cdot \mathrm{day}^{-1}$ from Turbuhaler have been found not to stunt statural growth during observation for $2-4$ yrs in controlled prospective studies $[15,29]$.

Influencing of lower leg growth is not the only possible systemic effect of inhaled steroids on bone. However, so far no studies have found any adverse effect on markers of bone and collagen metabolism by doses which do not adversely affect lower leg growth [25]. Therefore, as for cortisol excretion in urine, knemometry seems to be more sensitive than changes in markers of bone metabolism in detecting systemic effects, or differences in systemic effects, between exogenous steroids.

Earlier studies have found only a weak correlation between steroid-induced changes in cortisol excretion in urine and changes in growth rate of the lower leg [8]. However, knemometry has always been more sensitive than urinary cortisol excretion in detecting systemic effects, or differences in systemic effects, between exogenous steroids. Therefore, it was surprising that fluticasone, $200 \mu \mathrm{g} \cdot \mathrm{day}^{-1}$, was associated with a significant reduction in cortisol excretion in urine but no change in lower leg growth rate; not even a trend towards a reduction in lower leg growth rate was seen. The reason for this discrepancy between the present and earlier studies is not known. The clinical relevance of a small, but statistically significant, suppression of cortisol excretion in urine is not known. It would take studies conducted over longer periods of time and other assessments of the hypothalamic pituitary adrenocortical (HPA)-axis function to make such an assessment; however, practical experience suggests that it is not clinically important.

The error of the knemometry measurements in our study was a little smaller than in our previous studies. In all knemometry studies, including studies on healthy children, outliers and negative values of lower leg growth rate are reported. However, the incidence of extreme outliers in lower leg growth rate was a little higher in the present study. In the high-dose treatment arm, two extreme outliers (one during budesonide treatment and one during placebo treatment) markedly contributed to the statistical significance. Without these two measures, the mean growth rates during the various treatments would have been: placebo 0.49 ; fluticasone propionate 0.37 ; and budesonide $0.36 \mathrm{~mm} \cdot$ week $^{-1}$. 
The mean velocity of, and variation in, lower leg growth rate in the high-dose group during placebo treatment were similar to those observed during run-in and wash-out periods in several earlier trials of inhaled and oral steroids in similar patient groups and study designs, indicating that the method is highly reproducible [4, $7,19,30]$. However, the growth rate in the low-dose group during placebo treatment was markedly lower; the difference between placebo growth rates in the two groups being of a similar magnitude to the reduction in growth rate caused by the steroid treatments in the highdose group. A similar difference between groups of children has previously been reported in one other study [31]. We do not know the cause of this variation. The children in the two groups were comparable with respect to age, height, lung function and asthma severity, but not with respect to ratio between boys and girls. There was an overrepresentation of boys in the highdose group. However, the growth rate was the same for boys and girls, so we do not believe that this could explain the difference in growth rate between the two groups. Only the dose of inhaled corticosteroid varied. This finding supports the suggestion that knemometry is more suitable for short-term cross-over studies than for short-term comparisons of lower leg growth rates measured in different groups of children [25]. Therefore, comparisons of lower leg growth rates measured in different studies should be made with caution.

The present study group consisted of children with mild asthma because we wanted to minimize any possible influence on growth due to poorly controlled asthma. The results showed that this was achieved. As a consequence, a suppressive effect upon growth by the exogenous steroids could not be negated by a possible positive influence of a better asthma control. This situation is different from normal clinical practice, where inhaled corticosteroids in high doses are restricted to children with moderate and severe asthma. Furthermore, due to the mildness of the disease, no comparisons in clinical effect could be made between the two drug/inhaler combinations. Such comparisons would require the use of lower doses in patients with more severe disease and/or using other outcome measurements, including bronchial hyperreactivity [1].

Both in the low-dose group and in the high-dose group, there were no statistically significant differences between the two drug/inhaler combinations in any of the parameters studied. This strongly suggests that, dosefor-dose, budesonide Turbuhaler and fluticasone Diskhaler are associated with similar systemic effects. This is at variance with the findings in recent studies in adults [31-33]. These studies found somewhat higher systemic effects of fluticasone Diskhaler than budesonide Turbuhaler $[31,32]$. The reason for this discrepancy is not known. Diskhaler has a lower resistance than Turbuhaler. Therefore, the inspiratory flow rates are higher through Diskhaler. A high inspiratory flow rate is likely to cause a higher impaction of drug in the upper airways in children (and hence a lower intrabronchial deposition), due to their narrower upper airway diameter. Further studies are needed to make this assessment.

Since no statistically significant differences were found between the two drug/inhaler combinations in any of the safety parameters studied, it can be concluded that, dose-for-dose, budesonide Turbuhaler and fluticasone propionate Diskhaler have similar systemic effects in children with mild asthma.

\section{References}

1. Pedersen S, Hansen OR. Budesonide treatment of moderate and severe asthma in children: a dose-response study. J Allergy Clin Immunol 1995; 1: 29-33.

2. Price JF, Weller PH. Comparison of fluticasone propionate and sodium cromoglycate for the treatment of childhood asthma. Respir Med 1995; 89: 363-368.

3. MacKenzie CA, Weinberg EG, Tabachnik E, Taylor M, Havnen J, Crescenzi K. A placebo-controlled trial of fluticasone propionate in asthmatic children. Eur $J \mathrm{Pe}^{-}$ diatr 1993; 152: 856-860.

4. Wolthers OD, Pedersen S. Short-term growth during treatment with inhaled fluticasone propionate and beclomethasone dipropionate. Arch Dis Child 1993; 68: 673-676.

5. Wolthers OD, Pedersen S. Controlled study of linear growth in asthmatic children during treatment with inhaled glucocorticosteroids. Pediatrics 1992; 89: 839-842.

6. Wolthers OD, Pedersen S. Short-term linear growth in asthmatic children during treatment with prednisolone. BMJ 1990; 301: 145-148.

7. Wolthers OD, Pedersen S. Growth of asthmatic children during treatment with budesonide: a double-blind trial. BMJ 1991; 303: 163-165.

8. Wolthers OD, Pedersen S. Measures of systemic activity of inhaled glucocorticosteroids in children: a comparison of urine cortisol excretion and knemometry. Respir Med 1995; 89: 347-349.

9. Pedersen S. Safety aspects of corticosteroids in children. Eur Respir Rev 1994; 4: 33-43.

10. Gustafsson P, Tsanakas J, Gold M, Primhak R, Radford M, Gillies E. Comparison of the efficacy and safety of inhaled fluticasone propionate, $200 \mu \mathrm{g} \cdot$ day $^{-1}$, with beclomethasone dipropionate, $400 \mu \mathrm{g} \cdot \mathrm{day}^{-1}$, in mild and moderate asthma. Arch Dis Child 1993; 69: 206-211.

11. Dahl R, Lundback B, Malo J, et al. A dose ranging study of fluticasone propionate in adult patients with moderate asthma. Chest 1993; 5: 1352-1358.

12. Fabbri L, Burge PS, Croonenborgh L, et al. Comparison of fluticasone propionate with beclomethasone dipropionate in moderate to severe asthma treated for one year. Thorax 1993; 48: 817-823.

13. Agertoft L, Pedersen S. Importance of the inhalation device on the effect of budesonide. Arch Dis Child 1993; 69: 130-133.

14. Selroos O, Backman R, Forsen KO, et al. Clinical efficacy of budesonide Turbuhaler compared with that of beclomethasone dipropionate pMDI with volumatic spacer: a 2 year randomized study in 102 patients. Allergy 1994; 49: 833-836.

15. Agertoft L, Pedersen S. Effects of long-term treatment with an inhaled corticosteroid on growth and pulmonary function in asthmatic children. Respir Med 1994; 88: 373-381.

16. Agertoft L, Pedersen S. A randomized, double-blind, dose-reduction study to compare the minimal effective dose of budesonide Turbuhaler and fluticasone dipropionate Diskhaler. Am J Respir Crit Care Med 1996; 153 (4): A408.

17. MacKenzie CA, Wales JK. Knemometry and its practical application. Eur Respir Rev 1993; 3: 321-325.

18. Wolthers O, Pedersen S. Growth in asthmatic children 
during treatment with budesonide. Pediatrics 1992; 91: 517-518.

19. Wolthers OD, Pedersen S. Growth of asthmatic children during treatment with budesonide: a double-blind trial. BMJ 1991; 303: 163-165.

20. Pedersen S, Hansen OR. Treatment of asthmatic children with budesonide from a Turbuhaler and a MDI with a Nebuhaler. 35th Nordic Congress of Pneumonology. 1990; 35.

21. Pedersen S, Agertoft L. Relationship between shortterm lower leg growth and long-term statural growth in asthmatic children treated with budesonide. Am J Respir Crit Care Med 1995; 56: 13.

22. Karlberg J, Gelander L, Albertsson-Wikland K. Distinctions between short- and long-term human growth studies. Acta Paediatr 1993; 82: 631-634.

23. Karlberg J, Low L, Yeung CY. On the dynamics of the growth process. Acta Paediatr 1994; 83: 777-778.

24. Dean HJ, Schentag CT, Winter JSD. Predictive value of short-term growth using knemometry in a large population of healthy children. Acta Paediatr Scand 1990; 79(1): 57-63.

25. Wolthers OD. Knemometry in the assessment of systemic activity of exogenous glucocorticosteroids in children with asthma and rhinitis. MD Thesis. Copenhagen-Arhus-Odense, Publishers. 1996; ISBN 87-7749204-8.

26. MacKenzie CA, Wales JKH. Clinical experience with inhaled fluticasone propionate: childhood growth. Eur Respir J 1993; 6 (Suppl. 17): 262s.
27. Price J, Russell G, Hindmarsh P, Weller P, Heaf D. One year growth velocity in asthmatic children receiving fluticasone propionate, $50 \mu \mathrm{g}$ b.i.d or sodium cromoglycate, $20 \mathrm{mg}$ q.i.d. Am J Respir Crit Care Med 1996; 153(4): A409.

28. König P, Ford L, Galant S, et al. A 1 year comparison of the effects of inhaled fluticasone propionate (FP) and placebo on growth in prepubescent children with asthma. Eur Respir J 1996; 9 (Suppl. 23): 294s.

29. Merkus PJ, van Essen Zandvliet EE, Duiverman EJ, van Houwelingen HC, Kerrebijn KF, Quanjer PH. Longterm effect of inhaled corticosteroids on growth rate in adolescents with asthma. Pediatrics 1993; 91: 11211126.

30. Wolthers OD, Pedersen S. Knemometric assessment of systemic activity of once daily intranasal dry-powder budesonide in children. Allergy 1994; 49: 96-99.

31. Wolthers OD, Pedersen S. Short-term growth in children with allergic rhinitis treated with oral antihistamine, depot and intranasal glucocorticosteroids. Acta Paediatr 1993; 82: 635-640.

32. Lönnebo A, Grahnen A, Jansson B, Brundin RM, LingAndersson A, Eckernäs SÅ. An assessment of the systemic effects of single and repeated doses of inhaled fluticasone propionate and inhaled budesonide in healthy volunteers. Eur J Clin Pharmacol 1996; 49: 459-463.

33. Grahnen A, Eckernäs S, Brundin RM, Ling-Andersson A. Suppressive effect on the HPA-axis of single doses of fluticasone propionate in healthy volunteers. $\mathrm{Br} \mathrm{J}$ Clin Pharmacol 1994; 38: 521-525. 